\title{
Dental health largely ignored in NHS Long Term Plan
}

The recently published 10-year blueprint for the NHS in England has largely ignored oral health, much to the disappointment of dental leaders.

The NHS Long Term Plan, ${ }^{1}$ published on 7 January 2019, heavily focused on prevention and promising to stop an estimated 85,000 premature deaths each year thanks to:

- Planned action on large killer conditions

- Investment in world class, cutting edge treatments including genomic tests for every child with cancer

- Greater use of the latest technology such as digital GP consultations for anyone wanting them

- Early detection.

In its 136 pages, the Plan contains no chapter or even a paragraph heading for oral health. Dental care is only mentioned twice.

However, it does mention oral health in the context of holistic care for children and refers to Starting Well - the programme of dental practicebased initiatives designed to reduce oral health inequalities and improve oral health in children under the age of five years - that launched in 2017 in high priority areas.

The Plan refers to supporting dental services via the Starting Well initiative, claiming that it supports 24,000 dentists across England to 'see more children from a young age to form good oral health'

However, there is no commitment to any new investment for the programme, which is only active in a handful of wards in 13 English local authorities.

The BDA said it was a disappointment that despite a heavily trailed focus on both primary care and prevention, the government had 'failed to outline a coherent strategy for dental services' within the Plan.

It highlighted the fact that Prime Minister Theresa May launched the Plan at the Alder Hey Children's Hospital in Liverpool, a city where around 4,000 children have undergone hospital tooth extractions in the last five years, costing up to $£ 1$ million a year, saying
WHS

that tooth decay remains the number one reason for child hospital admissions.

The BDA said that since taking office, Health and Social Care Secretary Matt Hancock had often pledged to put prevention at the heart of NHS strategy, but had failed so far to invest in public health activity or make any tangible commitment to dentistry.

The plan does not address the NHS's workforce issues, including growing recruitment and retention problems in dentistry.

BDA Chair Mick Armstrong said: 'Warm words on prevention will ring hollow as the government fails to acknowledge the challenges facing 24,000 NHS dentists.

'The Prime Minister launched her strategy at a paediatric hospital, serving a city that spends $£ 1$ million a year extracting rotten teeth from children. We have faced year on year cuts, a recruitment and retention crisis, and have patients travelling over 50 miles to secure access to basic services. Now a single unfunded scheme is being offered as a substitute for proper resources and a coherent plan.'

However, the British Society of Paediatric Dentistry (BSPD) said the fact that children's oral health was mentioned in the context of holistic care for children in the Plan represented progress, considering that it had been excluded from earlier strategies for the NHS.

The document states that local areas should design and implement models of care that will 'support health development by providing holistic care across local authority and NHS services, including primary care, community services, speech and language therapy, school nursing, oral health, acute and specialised services.

Claire Stevens, spokesperson for BSPD, said: 'It's really good to see recognition for oral health in the NHS Long Term Plan. I am delighted that there is a mention for Starting Well, the prevention programme. We would like to see this extended into other areas where there are high levels of dental decay.'

1. Department of Health \& Social Care. The NHS Long Term Plan. 2019. Available at https:// www.longtermplan.nhs.uk/publication/nhs-long-term-plan/ (accessed January 2019).

\section{New edition of dental education book}

A new eighth and international edition of The Scientific Basis of Oral Health Education written by Dr Ronnie Levine and Catherine StillmanLowe has been published by Springer International Publishing.

The first edition of this classic text appeared in 1976 intending to refine and standardise the advice given to the public and ensure that such advice was scientifically sound and evidence-based.

It provides information and advice on the main aspects of oral health, including the cause and prevention of dental caries, periodontal disease, dental erosion, oral cancer and dental problems in children under five, and older people.
The authors are Dr Ronnie Levine, Honorary Senior Research Fellow in Child Health at the Academic Unit of Obstetrics, Gynaecology and Paediatrics, University of Leeds and Department of Oral Surgery, University of Leeds, and Catherine StillmanLowe, who managed the Health Education Authority's oral health education projects until leaving the NHS in 2001 and who is now a patient reviewer for The BMJ (British Medical Journal) and regular peer reviewer for the $B D J$.

The book is available at https://shop.bda.org/

the-scientific-basis-of-oral-health-education-8th-edition. 